\title{
A inserção feminina no mercado de trabalho e suas implicações para os hábitos alimentares da mulher e de sua família
}

The women insertion in the labour market and its implications for the food habits of women and their families

Cristina Teixeira Lelis ${ }^{1}$, Karla Maria Damiano Teixeira ${ }^{2}$, Neuza Maria da Silva ${ }^{3}$

${ }^{1}$ Mestre em Economia Doméstica pela Universidade Federal de Viçosa (UFV) - Viçosa (MG), Brasil.

crisecd@yahoo.com.br

2 Doutora em Ecologia Humana e Familiar pela Michigan State University - Michigan (MI), Estados Unidos. Professora Associada do Departamento de Economia Doméstica da UFV - Viçosa (MG), Brasil. kdamiano@ufvbr

${ }^{3}$ Doutora em Economia da Família e do Consumidor pela Purdue University - West Laffayette (IN), Estados Unidos. Professora Associada do Departamento de Economia Doméstica da UFV - Viçosa (MG), Brasil. neuzams@ufv.br
RESUMO Este estudo analisou os hábitos alimentares de mulheres inseridas no mercado de trabalho formal e de suas famílias. A pesquisa foi realizada na cidade de Viçosa/ MG. A amostra foi de 101 mulheres. Os dados foram obtidos através de uma entrevista fundamentada em um roteiro semiestruturado. $O$ estudo permite concluir que qualquer mudança na família, tal como a atividade remunerada exercida pela mulher, produz um remanejamento de funções. Os hábitos alimentares, apesar de sofrerem influência da atividade remunerada exercida pela mulher, não são totalmente diferenciados dos hábitos das donas de casa quando se analisa a inserção feminina no mercado de trabalho.

PALAVRAS CHAVE: Mulheres, Trabalho feminino, Hábitos alimentares.

ABSTRACT The study analyzed the eating habits of women included in the formal labor market and their families. The survey was conducted in Viçosa, Minas Gerais, using a sample of 101 women. Data were collected through a semi-structured interview. It was concluded that any change in the family, as for example the paid activity performed by the wife, produces a redistribution of the functions. Eating habits, despite being influenced by the paid activity performed by women, are not fully differentiated from the habits of housewives when it is regarded the inclusion of women in the labor market.

KEYWORDS: Women; Working women; Eating habits. 


\section{Introdução}

As mulheres vêm assumindo um espaço cada vez maior no mundo público do trabalho remunerado, um local que era majoritariamente masculino.

Essa inserção feminina no mercado de trabalho é um dos exemplos que pode contribuir para a alteração nos hábitos alimentares da mulher e de sua família. Isso porque as mulheres ainda são as responsáveis por $80 \%$ das atividades alimentares domésticas. Entretanto, principalmente nas sociedades ocidentais, elas procuram se liberar desses tipos de atividades, investindo em formação e informação e procurando exercer atividades profissionais que as valorizem socialmente e afirmem sua autonomia financeira (LAMBERT et al., 2005). Assim, a busca das mulheres por melhores condiçóes no mercado de trabalho pode comprometer o preparo das refeições, uma vez que elas são apresentadas como as principais responsáveis por essas atividades.

Para Pinheiro (2005), quando a mulher assume uma vida profissional extradomicílio, continua acumulando a responsabilidade sobre a alimentação da família, transitando entre o ambiente do trabalho e o doméstico. Assim, coloca-se como um novo paradigma da sociedade moderna, que não tem criado mecanismos de suporte social para a não concentração dessa atribuição enquanto unicamente feminina.

De acordo com Siliprandi (2004), as mulheres são vistas como um "instrumento" com o qual se atingirá a segurança alimentar das famílias, ou seja, elas são consideradas as guardiâs do bem-estar dos demais membros da família. Garcia (1997) argumenta que a colocação profissional e a independência da mulher afetam a estrutura da alimentação e provocam uma organizaçáo de valores e hábitos que podem trazer consequências no padrão alimentar familiar.

O custo de oportunidade ${ }^{1}$ do tempo da mulher está diretamente relacionado com a probabilidade de aquisição e dispêndio familiar com alimentos que demandam menor tempo de preparo, como os alimentos processados, e inversamente relacionado com a probabilidade de aquisição e dispêndio com alimentos tempo-intensivos (SCHLINDWEIN; KASSOUF, 2007).

Diversos autores, como Rodrigues e Sabes (2006) e Schlindwein e Kassouf (2007), entre outros, dizem que a alimentação fora de casa tem adquirido importância no cotidiano das pessoas devido à inserção da mulher no mercado de trabalho, distâncias entre casa e trabalho, além da falta de tempo para o preparo dos alimentos no lar. Comer fora de casa deixou de acontecer somente em ocasióes especiais e se tornou uma necessidade devido aos ritmos da vida cotidiana. Para Lambert et al. (2005), há uma modificação da dieta tradicional para uma dieta na qual as pessoas preferem produtos prontos para o consumo ou produtos que exijam pouca dedicação durante o seu preparo, como aqueles já cozidos ou pré-cozidos.

Entretanto, é importante ressaltar que o aumento do consumo de refeições prontas, da alimentação fora do domicílio e a opção pelo fast-food causam riscos à saúde da população, acometendo também as crianças, principalmente porque muitas doenças, como, por exemplo, obesidade, diabetes, pressão arterial, problemas cardíacos, câncer, entre outras, são causadas, em parte, por uma alimentação inadequada (SCHLINDWEIN; KASSOUF, 2007).

A principal questão que este artigo pretende discutir é: qual é o impacto da inserção feminina no mercado de trabalho nos hábitos alimentares da família e quais são as circunstâncias que podem minimizar esse impacto? Este trabalho faz-se importante uma vez que são escassos os estudos na literatura científica brasileira sobre a relação entre a inserção da mulher no mercado de trabalho e os hábitos alimentares da família. Segundo Sichieri et al. (2003), em geral, a maioria dos trabalhos de avaliação do consumo alimentar de populaçóes baseia-se no cálculo dos macronutrientes,

\footnotetext{
' Custo de oportunidade refere-se ao valor estimado que o indivíduo ou a família deixa de ganhar quando decide usar determinado recurso para um fim especíico. O custo está associado às satisfações ou insatisfações (resultados) procedentes dos bens que poderiam ter sido escolhidos. Em outras palavras, o indivíduo avalia se o fato de usar um recurso para determinado fim irá Ihe proporcionar maior ou menor satisfação do que se o recurso fosse utilizado para outro desígnio ou fosse substituído por outro recurso. Este conceito está relacionado com o princípio de substituição ou de troca dos recursos (DAMIANO TEIXEIRA, 2005, p. 72).
} 
no respectivo consumo calórico e no consumo dos micronutrientes.

\section{Metodologia}

Esta pesquisa, exploratório-descritiva, utilizou-se da abordagem qualitativa e foi realizada na cidade Viçosa/ MG, que pertence à Zona da Mata Mineira, localizada a uma distância de $225 \mathrm{~km}$ da capital, Belo Horizonte, e com uma populaçáo total estimada de 72.244 habitantes (IBGE, 2010). É uma cidade universitária e sua economia está centrada em torno da Universidade Federal de Viçosa (UFV) e do comércio local.

O universo do presente estudo foi constituído por mulheres que trabalhavam nos diferentes setores ocupacionais da UFV. A amostra foi composta por mulheres no estágio intermediário do ciclo de vida, ou seja, em cujas famílias havia presença de crianças a partir de 0 ano de idade e adolescentes de até 18 anos. No processo de obtenção dos dados das mulheres inseridas no mercado de trabalho, procurou-se a Pró-Reitoria de Gestão de Pessoas da UFV para identificar as possíveis participantes da pesquisa. Assim, calculou-se o tamanho da amostra, utilizando a fórmula para populações finitas, considerando um erro de $0,5 \%$, e encontrou-se que a amostra ideal seria composta por 56 docentes e 74 técnicas administrativas. Através da técnica do sorteio, procuraram-se as mulheres em seus departamentos e/ ou setores, explicando-lhes a pesquisa e indagando se se interessavam em participar. Durante o processo de contato com as mulheres, algumas delas não quiseram ou não puderam participar da pesquisa. Desse modo, totalizou-se 40 docentes e 61 técnicas administrativas entrevistadas.

Esta pesquisa foi aprovada pelo Comitê de Ética em Pesquisa com Seres Humanos, da Universidade Federal de Viçosa, sob o registro $n^{\circ}$ 0152/2010.

A coleta de dados foi realizada utilizando-se a entrevista fundamentada em um roteiro semiestruturado, tendo sido aplicada do mês de março ao de agosto de 2011, e gravada com a permissão das participantes. As entrevistas foram transcritas, preservando-se o anonimato das participantes, e o texto foi codificado e analisado utilizando-se o Software for Qualitative Data Analysis (MAXqda).

Os dados foram analisados por meio da análise de conteúdo. As categorias analíticas foram: perfil socioeconômico das mulheres e de suas famílias, sendo estudadas as variáveis: idade da entrevistada; estado civil; escolaridade; número de horas de trabalho por dia; renda em salários mínimos; e hábitos alimentares, que buscaram identificar as mudanças ocorridas nos hábitos alimentares com a inserção das mulheres no mercado de trabalho, os tipos de alimentos consumidos pelas famílias, o local onde realizavam as refeições, a situação da inserção no mercado de trabalho e o preparo das refeiçóes e a diferença das refeições de final de semana e durante a semana.

\section{Perfil socioeconômico das mulheres inse- ridas no mercado de trabalho e de suas famílias}

As entrevistadas tinham entre 27 e 58 anos, com idade média de 41,7 anos e média de 1,8 filhos. Quanto ao estado civil, a maioria era casada $(75,5 \%)$; seguido por união consensual $(9,9 \%)$; solteiras $(6,9 \%)$; separadas (3.9\%); divorciadas $(2,9 \%)$; e outros $(0,9 \%)$.

Quanto à escolaridade, $50,5 \%$ das entrevistadas possuíam pós-graduação Stricto Sensu, 24,8\% haviam concluído o ensino superior, 11,9\% haviam concluído pós-graduação Lato Sensu, 6,0\% possuíam ensino médio completo, 3,9\% estavam com ensino superior em andamento, 1,9\% com pós graduação Stricto Sensu em andamento, e 1,0\% possuía curso técnico. De acordo com o IBGE (2008), maiores níveis de escolaridade garantem melhores oportunidades de inserção qualificada no mercado de trabalho. $\mathrm{E}$, ainda, as mulheres brasileiras vêm se sobressaindo em relação aos homens, sobretudo nas áreas urbanas do País, onde apresentam, em média, um ano a mais de estudo que os homens.

No que tange à renda familiar, essa variou de $\mathrm{R} \$ 1.800,00$ a $\mathrm{R} \$ 20.000,00$, e a média foi de $\mathrm{R} \$ 7.415,84$. Com relação ao número de horas de trabalho remunerado, $84,2 \%$ das mulheres disseram 
trabalhar 8 horas diárias; 7,9\%, 10 horas/dia; 5,9\%, 6 horas diárias; 1,0\%, 9 horas/dia; e 1,0\%, 14 horas/dia.

\section{Trabalho remunerado da mulher e suas con- sequências para os hábitos alimentares}

De interesse para o estudo foi saber se a inserção feminina no mercado de trabalho ocasionou mudança nos hábitos alimentares da própria mulher e de sua família. No que se refere às técnicas administrativas, $63,9 \%$ afirmaram que os hábitos foram alterados. Para $8,2 \%$ das mulheres que afirmaram que não houve alteração nos hábitos alimentares devido à sua inserção no mercado de trabalho, outros fatores contribuíram para alteraçóes, como o nascimento dos filhos; a presença de filhos adolescentes que trazem novos hábitos de consumo para a família; e questóes de saúde. Para as docentes, $52,5 \%$ disseram que os hábitos foram alterados, sendo que $12,5 \%$ das que relataram que não houve alteração devido à sua inserção no mercado de trabalho afirmaram que a alteração aconteceu devido à sua idade, a problemas de saúde e à presença de filhos.

Para aquelas que relataram alteraçóes nos hábitos alimentares em decorrência da sua inserção no mercado de trabalho, a principal modificação foi a realização de refeições mais rápidas, com substituição de refeiçôes por lanches. Nas seguintes falas, pode-se perceber a alteração no hábito alimentar pessoal relatado pelas mulheres:

A gente come mais lanche, uma comida mais rápida. Acho que passa a comer mais fora, comida pré-preparada. Acho que isso mudou. (técnica administrativa, 44 anos, superior completo).

Almoçamos fora, então já mudou. E, como eu saio de casa na hora do almoço, e só chego $9 e$ pouca da noite, então tem que ser coisas práticas pra ele poder fazer, pra ele comer. (técnica administrativa, 45 anos, superior completo).

Pela questão do tempo. O tempo que a gente destina pra preparar, pra cortar os alimentos.
Então, com a inserção no mercado de trabalho a gente tem menos tempo pra cuidar da alimentação. Então, mudou o hábito sim. Em muitos casos, a gente come coisas mais rápidas, finais de semana, pelo cansaço. (docente, 45 anos, pós doutora).

Segundo Aquino e Philippi (2002), além da estabilidade econômica, outros fatores, como o trabalho da mulher fora do lar, maior praticidade, rapidez, durabilidade e boa aceitação do produto, vêm contribuindo cada vez mais para a introdução e manutenção de alimentos nos hábitos da família, dentre eles os industrializados. Essa questão estava muito presente nas falas das entrevistadas, conforme exemplificado a seguir:

Eu acho que, no meu caso, justamente por causa do pouco tempo, às vezes o corre-corre, você não se alimenta direito. Come besteira durante o expediente todinho, na hora de almoçar, você não almoça. No meu caso pessoal. (técnica administrativa, 37 anos, superior completo).

Ah! Houve, a gente passa a comer mais porcaria. A gente passou a comprar refrigerante pra filho, coisa que antes era suco natural. A gente passou a comprar mais produto industrializado. Eu lembro da época que eu fazia hambúrguer dentro de uma lata de óleo. Hoje você compra hambúrguer pronto. Então, assim, você tem poder aquisitivo, você vai comprar iogurte. Eu fazia coalhada em casa, que durava 1 semana, com copinho de iogurte natural. Entâo, com certeza, mudou muito. (docente, 40 anos, doutora).

Sdrali (2005), citado por Schlindwein (2006), refere-se que a entrada das mulheres no mercado de trabalho está relacionada com uma crescente autonomia e habilidade de tomar decisóes. Desse modo, a participaçáo da mulher no mercado de trabalho possui um papel significativo no gasto com alimentação.

Constatou-se que para algumas entrevistadas, a mudança ocorrida nos hábitos alimentares estava 
relacionada com a renda adquirida com o trabalho, o que aumentou a possibilidade de investir em alimentação. Porém, esse investimento, muitas vezes, estava relacionado à quantidade de alimentos que podiam ser adquiridos e não à preocupação com a qualidade nutricional dos mesmos, como pode ser verificado em alguns relatos:

Ah, modificou! Hoje vai mais salgadinho, enlatado, refrigerante, e antes não tinha isso. Era só o basicão mesmo. Até o financeiro também, né? Não é só o tempo. No entrar no mercado de trabalho, as coisas vão facilitando, né? (técnica administrativa, 44 anos, superior completo).

[...] Eu passei a ter acesso a produtos que não tinha condiçóes de comprar, né? (técnica administrativa, 38 anos, mestre).

[...] pode ter melhorado pelo poder aquisitivo né? poder se alimentar de outras coisas, mas quantitativamente, qualitativamente não. Eu sempre tive uma alimentação que considero muito saudável, então, assim, o trabalho pode ter influenciado de forma quantitativa, mas não qualitativa. (técnica administrativa, 50 anos, superior completo).

A refeição noturna foi apontada como uma das modificações na alimentação com a inserção no mercado de trabalho, conforme ilustrado pelas seguintes falas:

A gente não faz janta em casa, né? Ás vezes faz alguma coisa diferente, mais é lanche mesmo. E a gente tinha o hábito de jantar. Tudo direitinho. Chega em casa cansada, nem quer saber... (técnica administrativa, 27 anos, superior completo)

Modificou pra pior, mas mais à noite. Durante o dia, a alimentaçáo continua normal. (técnica administrativa, 41 anos, pós-graduação lato sensu)
De acordo com Ribeiro et al. (2011), mudanças no perfil de alimentos ingeridos vêm ocorrendo nos países em desenvolvimento, com a crescente substituição dos alimentos ricos em fibras, vitaminas e minerais, por produtos industrializados. O jantar vem sendo substituído pelo lanche, pois está ocorrendo uma redução do consumo de alimentos que habitualmente compóem as principais refeiçóes dos brasileiros, bem como o crescimento do consumo do pão francês. Essas transformaçôes geram a formação de novos padrôes dietéticos, podendo gerar diversas carências nutricionais.

Para outras entrevistadas, sua inserção no mercado de trabalho permitiu que houvesse melhoria na qualidade dos hábitos alimentares, principalmente no que se refere à rotina e à qualidade dos alimentos consumidos, como apontado a seguir:

É, na verdade melhorou. Porque na época de estudante, a gente passa uma fase meio atrapalhada de alimentação, né? Come na hora errada, porque tem prova. E, hoje em dia, não, a gente tem hora certa pra tomar café. Almoço todos os dias na mesma hora, jantar sempre na mesma hora, tenho uma rotina, $e$ não sai dela... (docente, 45 anos, doutora).

Melhorou. Porque a gente passa a ter conhecimento. Então, melhorou em termos nutricionais. Maior ingestão de fruta, iogurte. Eu passei a dar mais importância pra ter mais verdura, mais nutricional mesmo. (técnica administrativa, 51 anos, superior completo).

Outro fator importante observado foi que as entrevistadas disseram que ocorreu alteração nos hábitos alimentares, mas não em razão de sua inserção no mercado de trabalho, e sim devido ao nascimento dos filhos, às preocupaçóes com o processo de envelhecimento e com sua saúde. Com relação ao nascimento dos filhos, as entrevistadas relataram a preocupação de transmitir exemplos de uma boa alimentação. Epstein et al. (2001), citado por Rossi, Moreira e Rauen. (2008), estudando 27 crianças, com idades entre 6 e 11 anos, e 27 pais, verificaram que a diminuição da 
ingestão alimentar de gordura e açúcar pelas crianças pode ser obtida por mudanças dos hábitos alimentares dos pais. Além disso, a melhoria do hábito alimentar dos pais pode estender-se a todos os outros membros da família. Nas falas seguintes, nota-se a alteração após o nascimento dos filhos:

Não por causa do trabalho, por causa da criança. Porque o trabalho, na realidade, se a criança não existisse, desde que eu comecei a trabathar, a gente come muito fora, almoça fora, não tem hábito de tomar café em casa, toma café na rua. Mas ai eu conjuguei o trabalho com a criança, pra te falar esta mudança, né? A criança que alterou propriamente. O trabalho, náo consigo te dizer o que pode ter alterado. (técnica administrativa, 30 anos, superior completo).

Mudou depois que a minha filha nasceu. Antes eu comia muita coisa assim pronta e comia de qualquer jeito, qualquer coisa, às vezes almoçava, às vezes não almoçava, às vezes jantava, às vezes não jantava também. A minha vida era muito irregular né. (docente, 43 anos, pós doutora).

Quanto à preocupação com a saúde, o principal motivador foi a disponibilidade de informaçóes e a facilidade de acesso a elas. Neste sentido, as entrevistadas alteraram seus hábitos alimentares a fim de terem uma alimentaçáo saudável, conforme relatos a seguir:

Eu não acredito que seja por causa da inserção no mercado de trabalho não. Acho que os hábitos mudam sim, mas na medida que a gente se preocupa mais com a alimentação. Acho que a idade leva a isso. A disponibilidade mudou muito da época. A disponibilidade de alimentos, a variedade, a diversidade, muito diferente da época.(...) Esta quantidade de informação a respeito de determinados tipos de alimentos. Isso a todo momento é novidade, a gente acaba incluindo. Então, muda. Eu acho que é uma coisa muito dinâmica. (docente, 53 anos, doutora).

No que se refere ao processo de envelhecimento, algumas entrevistadas relataram a preocupaçâo em evitar ou reduzir a quantidade ingerida de determinado alimento, a fim de permanecerem saudáveis durante as diferentes etapas de seu ciclo de vida, conforme mencionado:

[...] porque depois de uma faixa etária, por exemplo, a que eu estou hoje, ai há uma mudança que eu acho que é muito mais por uma questão de idade mesmo do que pela minha inserção no mercado. Você muda a sua alimentação. Você já náo come arroz, por exemplo, você come muito menos, mesmo uma fritura ou uma comida mais pesada, a carne, por exemplo. Eu já não tenho tanto apetite para carne. (docente, 47 anos, doutora).

Entre aquelas mulheres que disseram que o hábito alimentar não foi alterado com a entrada no mercado de trabalho, observou-se que os motivos estavam relacionados à presença de empregadas domésticas, reserva de um tempo para preparar a alimentação e residir próximo dos pais. Algumas falas ilustram essas questōes.

Porque eu gosto de cozinhar, gosto que as coisas sejam feitas em casa, então, sempre foi assim. Apesar de eu trabalhar fora, eu arranjo um tempinho pra deixar alguma coisa pronta, um bolo, uma coisa assim, mais natural. Acho que não modificou não. A gente não come muito fora, mais em casa mesmo. (técnica administrativa, 39 anos, mestre).

Não, porque desde quando eu comecei a trabalhar, eu coloquei uma ajudante dentro de casa, então ela ficou responsável pela preparação do almoço e tudo. Então a rotina que a gente tinha, a gente continuou mantendo. Então não atrapalhou não. (técnica administrativa, 36 anos, mestre). 
O estabelecimento de redes de apoio, sejam elas formais ou informais, permite ou facilita que atividades do cotidiano familiar, como o preparo das refeiçóes, não sejam modificadas quando a mulher ingressa no mercado de trabalho.

\section{O Consumo de alimentos pelas mulheres e suas famílias}

Com relação aos itens do consumo alimentar dos quais as famílias faziam uso, constatou-se que $100 \%$ das famílias das técnicas administrativas e $97,5 \%$ das docentes faziam uso de pelo menos um tipo de alimento industrializado, como iogurte, biscoito, suco de caixinha, enlatados e refrigerante. Algumas falas ilustram essa questão:

Suco de caixinha não muito, mas o resto dos industrializados: tudo. Minha filha ama. (...) Eu sou apaixonada por refrigerante. (técnica administrativa, 51 anos, superior completo).

Milho verde, massa de tomate. Estas coisas normais. Não somos muito fã assim de muita coisa enlatada não. Tem biscoito de polvitho, ou biscoito água e sal, biscoito maria. E aqueles nuggtes, eles (filhos) gostam também. Aqueles salgadinhos de frango, pão de queijo. Este tipo de coisa. (técnica administrativa, 38 anos, superior completo).

É importante ressaltar a contradição presente em alguns depoimentos: ao mesmo tempo em que procuram ter um discurso que demonstre uma preocupação em ter uma alimentação saudável, controlando o consumo de determinados alimentos durante a semana ou afirmando que prepararam alimentos naturais, principalmente sucos, o consumo de alimentos industrializados foi muito expressivo nas falas. O relato de tal preocupação talvez tenha sido em decorrência daquilo que elas achavam que a pesquisadora esperava ouvir, principalmente por serem mulheres com alto grau de instruçáo e que, portanto, tinham acesso a informaçóes sobre alimentação.

Os alimentos industrializados têm recebido atenção dos consumidores, que passaram a adotá-los devido, principalmente, à sua praticidade. Conforme Fonseca et al. (2011), o comensal moderno está familiarizado com a produção industrial e tem apreciado sua regularidade e conforto de uso. Além disso, o alimento industrializado apresenta status de modernidade. Nos depoimentos que seguem, podemos observar essas informaçōes:

Justamente pela praticidade de fazer. Relacionado à questão do trabalho, a correria, que é mais fácil de fazer, você acaba pegando o que é mais industrializado, que é mais prático pra fazer, imediato também. (técnica administrativa, 37 anos, superior completo).

É a praticidade. Mesmo quando eu tenho tempo pra fazer as coisas, se eu tenho industrializado, ele é mais prático, ele me convém mais. A gente não é mais tão paciente quanto era a máe da gente. (docente, 49 anos, doutora).

Além do consumo de alimentos industrializados, fazer as refeiçóes fora de casa virou uma necessidade da sociedade contemporânea (FONSECA et al., 2011). Dessa forma, outro item do consumo alimentar analisado foi a alimentação realizada fora do domicílio, uma vez que a Pesquisa de Orçamentos Familiares (2008/09) revelou que as famílias estão gastando mais com alimentação fora de casa do que gastavam na pesquisa realizada em 2002/03.

Assim, constatou-se que $90 \%$ das famílias de mulheres docentes e 65,6\% das famílias de técnicas administrativas faziam as refeições fora do domicílio. Consideraram-se, nesse caso, todas as pessoas que realizavam refeiçóes fora de casa, independente da frequência.

Analisando famílias nas quais pelo menos um dos membros fazia as refeiçóes fora de casa durante 
os dias da semana, $26,2 \%$ das famílias de mulheres técnicas administrativas e $20 \%$ das docentes realizavam as refeições fora do domicílio.

Enquanto 70\% das docentes realizavam de 1 a 6 refeições por mês fora de casa, esse percentual era de $39,4 \%$ para as técnicas administrativas, sendo observado que essas refeiçóes eram realizadas, na maioria das vezes, nos finais de semana.

Os principais motivos relacionados para almoçarem fora de casa, principalmente nos finais de semana, foram a falta da empregada doméstica nesse período, preguiça e lazer.

Do total das famílias pesquisadas, 75,2\% (76 famílias) realizavam refeiçóes fora de casa. Dessas famílias, $72,4 \%$ (55 famílias) o faziam em locais que serviam comida do tipo fast-food, principalmente o self-service.

Jomori et al. (2008) comentam que o restaurante por peso, ou self-service, tem sido muito frequentado por brasileiros. Nele, o comensal escolhe o que deseja consumir, pagando valor referente ao peso do que foi colocado em seu prato. Nesse sistema, há uma oferta ampla de opçóes de preparaçóes alimentares, delegando uma certa autonomia ao comensal para escolher.

\section{Rotina do preparo e realização de refeições para as mulheres e suas famílias}

Das 101 mulheres entrevistadas, 90,1\% disseram que as refeiçóes de final de semana eram diferentes das refeições de durante a semana, e 9,9\% disseram que não eram diferentes. Entre as razôes da diferença, estavam: comer várias vezes ao dia, maior tempo de preparo das refeiçóes, variedade de alimentos preparados, consumo de alimentos diferentes dos consumidos durante a semana, momento de reunir a família, preparo de refeiçóes rápidas e simples. Os seguintes depoimentos exemplificam:

Tem mais tempo pra preparar. Tem aquele momento pra fazer as refeiçóes. Os próprios meninos já falam, 'comida hoje tá melhor, comida hoje tá boa'. Faz mais variedade, você tem um pouquinho mais de tempo pra fazer, pra inventar. (técnica administrativa, 37 anos, superior completo).

Porque você acaba comendo uma coisa mais elaborada. Uma coisa que demore mais tempo pra fazer, você dispóe de mais tempo pra aquilo, né? (técnica administrativa, 52 anos, superior incompleto).

Porque eu faço, porque a gente faz junto. Porque a gente faz mais devagar. Ou porque a gente resolve ir lá no restaurante $x$, pra comer fora. Porque a mamãe deixa tomar refrigerante. A mamãe deixa comer batata frita, coisa que durante a semana nem passa pela cozinha. Então, é diferente sim. Bem diferente. (docente, 39 anos, doutora).

É importante ressaltar que o preparo das refeiçôes durante os finais de semana é considerado um momento de lazer, de união da família e de sair da rotina. Enquanto, para umas, era o momento em que se poderia incrementar a alimentação fazendo pratos mais elaborados, para outras, as refeiçóes de final de semana eram mais simples, principalmente devido à falta de empregada doméstica ou à necessidade de ter mais tempo livre.

Além disso, para cerca de 23,8\% das mulheres, a alimentação era pior aos finais de semana devido a falta de horários estabelecidos para a realização das mesmas, assim como ao valor nutricional dos alimentos ingeridos. As falas seguintes ilustram essa questão:

São diferentes pra pior. Porque eu estando em casa, a gente acaba comendo de forma mais desregulada, comendo toda hora, né? Então é pra pior. (técnica administrativa, 38 anos, mestre).

Em termos de qualidade nutritiva, elas são piores, risos. Porque final de semana você quer fazer uma carne, faz uma coisa diferente. Durante a semana, a coisa funciona direitinho, final de semana tudo errado. A gente faz uma 
coisa mais gordurosa um pouquinho. Às vezes, as refeiçóes de final de semana são piores em termos de qualidade de saúde. (docente, 33 anos, doutora).

É interessante observar que, ao estarem inseridas no mercado de trabalho, a mesma rotina destinada ao trabalho remunerado se aplica à alimentação. Em outras palavras, as mulheres buscam se alimentar de maneira mais nutritiva e em horários estabelecidos durante a semana, sendo que aos finais de semana não há compromisso com o horário e com o valor nutritivo da alimentação. Essa pode ser uma maneira de se sentirem mais relaxadas e de descansarem da rotina de trabalho.

Ao contrário, outras mulheres (18,8\%) buscavam se dedicar a esse preparo durante os finais de semana, a fim de ingerirem alimentos que consideravam mais saudáveis, principalmente pelo fato de realizarem as refeiçóes fora de casa durante a semana.

São, porque eu que faço. Muito mais saudável, porque comida de restaurante, elas não são tão saudáveis como a gente acha que são. Mas é a única opção que eu tenho. Durante a semana eu náo tenho este tempo, ai durante o final de semana, sábado e domingo, eu que faço. (técnica administrativa, 51 anos, superior completo).

Ah, eu acho que é uma coisa mais, uma comida bem mais caseira. Às vezes, chega a ser coisas mais leves, porque eu mesmo que preparo. Tento fazer o mais natural possivel, sem congelados, sem muito enlatado, coisas mais natural mesmo. Não muita variedade, mas umas coisas mais naturais. (técnica administrativa, 37 anos, pós-graduação lato sensu).

Talvez pelo fato de as mulheres terem uma rotina de trabalho remunerado com muitas responsabilidades, além de exercerem o trabalho doméstico, mesmo contando, muitas vezes, com o auxílio da empregada doméstica, durante os finais de semana elas parecem querer flexibilizar o tipo de alimento e se 'desobrigar' do cumprimento de horários como uma forma, talvez, de amenizar o cansaço e o estresse gerado pelo cumprimento de suas obrigaçóes.

\section{Conclusões}

O estudo realizado permite concluir que, para grupos homogêneos, em termos de renda e nível educacional, os hábitos alimentares, apesar de sofrerem influência, não são totalmente diferenciados quando se analisa a inserção feminina no mercado de trabalho. Outros fatores parecem exercer maior influência sobre isso, como a renda, o tipo de trabalho remunerado realizado, presença ou não de empregada doméstica, a estrutura familiar e as preferências pessoais e familiares.

A mudança dos hábitos, ocasionada pela inserção no mercado de trabalho, está relacionada à compra de alimentos industrializados, de comidas mais rápidas para o consumo, à modificação da alimentação noturna e a mudanças atreladas à melhoria do hábito alimentar. Outros fatores, como nascimento de filhos e inquietaçóes com relação à saúde e idade, também são variáveis que ocasionam transformações alimentares.

Os alimentos industrializados têm uma expressiva utilização, mesmo para as mulheres que não trabalham fora de casa, devido à praticidade e à facilidade de uso. Eles vêm, com a realização de refeiçôes fora de casa e com a flexibilização dos horários das refeições durante, principalmente, os finais de semana, 'liberar' as mulheres de suas obrigaçôes domésticas ou facilitar o seu desempenho. Assim, a mulher 'multifuncional' consegue minimizar o estresse e o cansaço decorrentes do exercício de múltiplas atividades.

É importante considerar os fatores de ordem geográfica, uma vez que a cidade de Viçosa é considerada de pequeno porte. Assim, há maiores possibilidades de realizarem refeiçóes em casa, mesmo que essas sejam preparadas por outras pessoas. Além disso, o estilo de vida é diferente se considerarmos uma cidade grande ou uma metrópole. 


\section{Referências}

AQUINO, R. C.; PHILIPP, S. T. Consumo infantil de alimentos industrializados e renda familiar na cidade de São Paulo. Revista de Saúde Pública, São Paulo, v.36, n.6, p. 655-660, 2002.

DAMIANO TEIXEIRA, K. M. A administração de recursos na família: Quem? Como? Por quê? Para quê? Viçosa: Editora UFV, 2005. 94p.

FONSECA, A.B. et al. Modernidade alimentar e consumo de alimentos: contribuições sócio-antropológicas para a pesquisa em nutrição. Ciência \& Saúde Coletiva, Rio de Janeiro, v.16, n 9, p. 3853-3862, set. 2011.

GARCIA, R. W. D. Práticas e comportamento alimentar no meio urbano: um estudo no centro da cidade de São Paulo. Cadernos de Saúde Pública, Rio de Janeiro, v.13, n.3, p. 455-467, jul./set. 1997.

INSTITUTO BRASILEIRO DE GEOGRAFIA E ESTATÍSTICA (IBGE). Cidades@. Rio de Janeiro: IBGE, 2011. Disponível em: <http:// www.ibge.gov.br/cidadesat/topwindow.htm?1>. Acesso em: 19 jul. 2011.

Síntese de Indicadores Sociais: uma análise das condições de vida da população brasileira. Rio de Janeiro: IBGE, 2008. Disponível em: <http://www.ibge.gov.br/home/estatistica/populacao/ condicaodevida/indicadoresminimos/sinteseindicsociais2008/ indic_sociais2008.pdf>. Acesso em: 4 fev. 2012.

JOMORI, M. M.; PROENÇA, R. P. C.; CALVO, M. C. Escolha alimentar: a questão de gênero no contexto da alimentação fora de casa. Caderno Espaço Feminino, v.19, n.1, p. 369-384, jan./jul. 2008.

LAMBERT, J. L. et al As principais evoluções dos comportamentos alimentares: o caso da França. Revista de Nutrição, Campinas, v.18, n. 5, p. 577-591, out. 2005.

PINHEIRO, A. R. O. A alimentação saudável e a promoção da saúde no contexto da segurança alimentar e nutricional. Saúde em Debate, Rio de Janeiro, v. 29, n. 70, p. 125-139, 2005.
RIBEIRO, M. M. C. et al. Impacto do hábito de jantar sobre o perfil dietético de pacientes em hemodiálise. Jornal Brasileiro de Nefrologia, São Paulo, v.33, n.1, p. 69-77, 2011.

RODRIGUES, F. S.; SABES, J. J. S. A percepção do consumidor de alimentos "fora de casa": um estudo multicaso na cidade de Campo Grande/MS. Caderno de Administração, Bauru, v. 14, n.2, p. 37-45, 2006.

ROSSI, A.; MOREIRA, E. A.M.; RAUEN, M.S. Determinantes do comportamento alimentar: uma revisão com enfoque na família. Revista de Nutrição, Campinas, v.21, n.6, p. 739-748, nov./dez. 2008.

SCHLINDWEIN, M. M. Influência do custo de oportunidade do tempo da mulher sobre o padrão de consumo alimentar das famílias brasileiras. 2006. 119 p. Tese (Doutorado em Ciências) - Escola Superior de Agricultura Luiz de Queiroz, Universidade de São Paulo, Piracicaba, 2006.

SCHLINDWEIN, M. M.; KASSOUF, A. L. Influência do custo de oportunidade do tempo da Mulher sobre o padrão de consumo alimentar no Brasil. Pesquisa e Planejamento econômico, Rio de Janeiro, v.37, n.3, p. 489-520, dez. 2007.

SICHIERI, R.; CASTRO, J. F. G.; MOURA, A. S. Fatores associados ao padrão de consumo alimentar da população brasileira urbana. Cadernos de Saúde Pública, Rio de Janeiro, v. 19, sup. 1, p. 47-53, 2003.

SILIPRANDI, E. Políticas de segurança alimentar e relações de gênero. In: FARIA, N; NOBRE, M. (Orgs.). A produção do Viver. São Paulo, 2004.

Recebido para publicação em Março/2012

Versão definitiva em Novembro/2012

Suporte financeiro: Fundação de Amparo à Pesquisa do Estado de Minas Gerais (FAPEMIG)

Conflito de interesse: inexistente 